\title{
JUAN RULFO: CRITICA RECIENTE
}

\author{
POR. \\ GUSTAVO C. FARES \\ University of Pittsburgh
}

Juan Rulfo es uno de los autores cuya obra parece cada vez más reducida en comparación con el cúmulo de cstudios y análisis críticos que sobre la misma aparecen constantemente. En cstas líneas comentaremos algunas de las últimas y más valiosas aportaciones al estudio de la obra de este autor. Comenzamos con la rescña del libro de Lorente-Murphy que ubica a la obra de Rul fo en la circunstancia socio-histórica que relata. El texto de esta obra es estudiado por Pcavler, cuyo último libro comentamos a continuación. Finalmente, Aronnc-Amestoy y Dixon accrean dos interpretaciones distintas de Pedro Páramo.

El cstudio de Lorente-Murphy estudia las situaciones históricas a las que, directa o indirectamente, se refiere la obra de Rulfo. La introducción esboza la biografía del autor, a la vez que lo sitúa en relación a las corrientes litcrarias inmediatamente anteriores a su ćpoca, tanto de Europa como de América, lo cual permite rastrear las influencias literarias en Rulfo de los escritores nórdicos. Según la autora, Rulfo "no puede ser comprendido en toda su profundidad si no se lo coloca en cl marco histórico de la Revolución Mexicana y la posterior guerra de los "Cristeros'"(p. 6) Entonces Murphy ubica históricamente el fenómeno de la Revolución, y traza una cronología de los gobiernos que se suceden en México desde 1910 hasta los años cincuenta, en los que Rulfo escribe. El saldo que para cntonces deja el movimiento revolucionario es de fracaso, parálisis social y cscepticismo.

La litcratura se encargó en esos años no sólo de exaltar las virtudes de la Revolución, sino también de provecr las visiones críticas que cra imposible intentar desde el terreno político, a riesgo de ser tachado de contarrevolucionario por el partido institucional. Esta cmpresa crítica comenzó ya con los autores criollistas, culminando con Rulfo quien, hablando desde la voz del pucblo que perdió la revolución, desmonta el mito en el cual aquella se ha convertido, "dejando al desnudo la realidad más permanente y dolorosa del pucblo mexicano: su continua postcrgación." (p. 26) 
En los capítulos que siguen, la autora analiza "El llano en llamas" primero, y Pedro Páramo despućs, en sus temas y en sus formas narrativas, concluyendo que Rulfo, con su obra, ha desarticulado el mito de la Revolución.

En el estudio de los cuentos, se tiene en cuenta la realidad histórica referida por los relatos, y se trata de encontrar la crítica social implícita en cada uno de cllos. Así, "El llano en llamas" muestra las acciones de las bandas armadas postrevolucionarias que habían comenzado luchando por la igualdad y la justicia social, y que tcrminan sicndo "bandoleros homicidas"(p. 34). "Nos han dado la Lierra" critica las acciones del gobierno en el reparto de ticrras, la burocracia, y cl fracaso de la reforma agraria para mcjorar la vida de los más necesitados. "El día del derrumbe" muestra a uno de los funcionarios del gobicrno en una comunidad campesina, a la vez que completamente alejado de la realidad que alli ve. Es interesante que cl político enfatice la mitología de la Revolución, mediante la descripción de los "hérocs" nacionales, a los que el pucblo no reconoce. "Luvina" mucstra la relación entre el pucblo y el gobierno, éste último personalizado con referencias a su madre, una manera figurada de criticar el proceso que lo constituyó. "Paso del Norte" narra la experiencia, contemporánca a Rulfo, de emigrar a los Estados Unidos en busca de mejores condiciones laborales. El vínculo entre padre e hijo en "La herencia de Matilde Arcángcl" cs, para la autora, una metáfora de la relación gobierno-pucblo, al igual que "iDíles que no me maten!" y "Acućrdate" mucstran implícitamente la crítica a una vida pucblerina sin incentivos ni motivaciones, rodeada de ignorancia. El mismo tipo de vida es cl que se describe en "Macario", rclato en el que un subnormal 'platica' acerca de su existencia y de las condiciones en las que habita con su tutora y su nana, rodeado de superstición, religiosidad mal entendida, demonios y respeto ciego a la autoridad. La superstición en la que vive el pucblo aparece nuevamente en "Talpa" y en "Anacleto Morones." "La cuesta de las Comadres" y "En la madrugada" son testimonio de las condiciones en las que subsiste el campesino de Jalisco, del fenómeno de despoblación del campo, y de las relaciones entre las distintas clases socialcs. "Es que somos muy pobres" es el resultado del tipo de vida hasta aquí descripto, y que, narrado desde la óptica de un niño, muestra las consecuencias de las situaciones de pobreza. "La noche que lo dejaron solo" se refiere expresamente a un incidente de la guerra de los "Cristeros".

En los cucntos, se muestra más de lo que se dice, y esto constituye su mejor crílica. Los seres elementales que vemos, la violencia inútil en la que viven, su pobreza, el despoblamiento de sus tierras, y la carencia de perspectivas de progreso, a pesar de haber sido protagonistas, a la vez que víctimas, de un proceso revolucionario, sirven para desmontar el andamiaje mitológico de la Revolución Mexicana. 
En cl capítulo segundo acerca de Pedro Páramo la autora afirma que Rulfo hace otro tanto, trascendiendo los límites espacio-temporales de la situación histórica, para pasar a tener connotaciones de carácter universal. Para LorenteMurphy cl mayor valor de la obra se encuentra en el tratamiento del tema, más que en el tema mismo. Luego de hacer un análisis de los recursos que Rulfo emplea cn su novela, pasa a tratar la estructura dual de la obra, y la relaciona con el tema del caciquismo. Para la autora, la búsqueda personal de Juan Preciado sirve de imagen para retratar la búsqueda de identidad nacional y cultural del pucblo mexicano. La auscncia del padre fue un fenómeno real en los hogares campesinos, ya que más de una gencración de hombres fuc diezmada por las luchas revolucionarias. Se entiende que éste no es el caso de Juan, aunque su situación de huérfano le sirve a la autora para hablar de la realidad del campo jaliscience en la época revolucionaria. Esta se refleja expresamente, en el diálogo que Pedro Páramo mantiene con el Tilcuate y en cl cual se da breve cuenta de los avatares de la contienda. Comala, entonces, scría la imagen acabada del México post-revolucionario.

El tema del caciquismo es tratado extensamente, y se buscan los referentes históricos de los que cs el reflejo, en especial, de la figura de Porlirio Díaz. Murphy menciona los antecedentes literarios de Pedro Páramo como figura de cacique, y las influencias que este personaje tuvo en la litcratura posterior. Este tema, y la manera como está tratado en Pedro Páramo abre, para la autora, una esperanza, ya que la muerte de Páramo anuncia que el cacique deja de ser una realidad histórica, y que cl cacicazgo como institución deja paso a formas participativas más efectivas; cl parricidio de Abundio asi nos lo hace saber.

Frentc a una lectura de la crítica mítica y a otra existencial, la autora llama la atención accrca de "el resultado desmistificador de la obra de Rulfo" y enfatiza que la imagen literaria que él compone no es caprichosa, sino que responde a una realidad verificable "cuyo origen está en su ticrra natal y en una situación social, política y cconómica determinada." (p. 98)

En cl capítulo tercero estudia las formas narrativas de Rulfo, y las clasifica en: cl trastocamiento de la cronología; la repetición de frases, ideas y situaciones; cl laconismo del estilo; el juego con los silencios; el recurrir al habla "típicamente rural" de los personajes, de la que la autora apunta algunos ejemplos; una actitud de indiferencia frente a hechos inusiladamente brutales. Un análisis del lenguaje de Rulfo, de los usos que da a los sustantivos, adjetivos, verbos y adverbios, completa cl cstudio de su estilo.

Murphy concluye que Rulfo, al hablar de la Revolución desde dentro de ella misma, como siendo parte del tema cn sí, muestra más que demuestra. El contenido de las obras, a su vez, determina los recursos estilísticos del autor. Los textos, en 
su conjunto, desmontan el mito de la Revolución Mexicana, de la que han quedado "una terminología, unas imágenes, decoraciones, anécdotas y motivos artísticos" (p. 125), pero en el fondo, un gran vacío. Murphy opina que los progresos materiales del pucblo mexicano se hubicran obtenido de cualquicr manera, con o sin revolución, y que ésta lo que ha hecho es reforzar las formas tradicionales de dominio.

En relación a la forma de la obra de Rulfo, no de los estudios necesarios y aún pendientes, es el que emprende Peavler en su libro. En él trata acerca de las diferentes ediciones de Pedro Páramo, sus coincidencias y diferencias, y los efectos que cllas producen en la significación del texto. Al lecr las desavenencias entre las diferentes ediciones de la obra, parece que se está frente a un texto del cual no cxiste un original o que ćl mismo, si alguna vez existió, es uno más entre las múltiples versiones, todas verdaderas, que de él hay.

En la introducción, luego de pasar revista a sus predecesores en la tarea de interpretar a Rulfo, se identifican los propósitos del libro: tratar de llegar a un acuerdo acerca de los dalos válidos para interpretar la obra, antes de abocarse a estudiarla. Dice cl autor que cl estudio que emprende "pretende aciarar y comentar los textos mismos: no cl contenido, no el significado, no la interpretación, sino explorar lo que las narraciones nos of recen, sus claves e indicios, y cómo podemos proceder a partir de esta información." Y más adclante repite que "El propósito es desenredar las narraciones ... para mcjorar la lectura y la comprensión del texto." (p. 4)

El libro no se limita, sin embargo, a hacer sólo cso, sino que en el segundo capítulo incluye una interprctación de los relatos de El llano en llamas, desentrañando los problemas que cl concepto de 'punto de vista' acarrea, por el hecho de comprender dos elementos distintos: el de la perspectiva, es decir, el de la mirada que observa, a la vez que cl de la voz que habla. En cada cuento, y basándose en las icorías de Gérard Genctte, Peavler distingue dos conceptos: el de la voz que habla y el de la mirada que observa. Dicha distinción prucba ser fructífcra y esclarecedora, a la vez que revela la complejidad del estilo rulfiano.

El capítulo tercero es el dedicado a desentrañar el texto 'original' de Pedro Páramo, para lo cual se citan las siguientes ediciones de la obra: la primera de 1955, la de la colección popular del Fondo de Cultura Económica de 1964, la de Appleton-Century-Crofts de 1970, y la de la Colección Popular de 1981, "revisada por el autor." Pcavler no incluye en csta lista la edición del año 1983 de Gonzálcz Boixo en la cditorial Cátedra, ni la de 1983 de la editorial Scix Barral en su colección Biblioteca Breve.

Se examinan detenidamente dos ediciones: la de 1964 y la de 1981. La primera es tomada comọ punto de referencia por su "ubicuidad" y su "peso", 
siendo, asimismo, la edición más comentada; la segunda, del año 1981, se tiene cn cuenta debido a que es la edición que apareció en la Colección Popular del Fondo de Cultura Económica como "revisada por el autor." En la edición de la novela realizada por González Boixo se reproducen, justamente, unas declaraciones de Rulfo acerca de esta última, en las que aclara que la cdición de la obra hecha por cl Fondo de Cultura en la colección de Letras Mexicanas, se realizó en base a un borrador de Pedro Páramo, ya que el original estaba en el Centro Mexicano de Escritores. En 1980 el director del Fondo encontró el original en el Centro Mexicano de Escritores, y le sugirió a Rulfo editar el original, a lo que éste accedió. La edición de 1981, pues, se trata de la del original de la obra, y no de una revisión.

Pcavler recurre al método de identificar los fragmentos por las sangrias que cncuentra al principio de cada uno. De esta manera detecta 66 fragmentos en la primera edición, $68 \mathrm{en}$ la de la Colección Popular, 66 en la edición hecha por Luis Leal en los Estados Unidos, y $70 \mathrm{cn}$ la de 1981 . El apéndice 2 establece con detalle los fragmentos de la obra en las ediciones de 1964 y de 1981. Las variaciones fundamentales de las diferentes ediciones se dividen en tres clases: estructurales, lingüísticas y visuales. Analiza el autor cómo aparece cada una de estas clases de desacuerdos y la influencia que tienen en la obra, a partir del estudio de las ediciones de 1964 y de 1981.

En el cuarto capítulo, Pcavler utiliza la interpretación del capítulo uno, referida al punto de vista de las narraciones, y lo revelado por el cstudio del texto de la novela en sus diferentes ediciones, para "desenredar" las historias de Juan Preciado y de Pedro Páramo. Se propone aquí aclarar los desacuerdos entre los críticos acerca de quién narra, quién vive, si se puede establecer una cronología de las acciones, y si cs posible hablar de "tiempo" en un sentido tradicional. Como hace González Boixo (Claves), Peavler identifica varios niveles narrativos que se reconocen, ya mediante el uso de signos de puntuación, ya por la continuidad y repetición de temas o leitmotifs. A través de las micronarraciones, estos temas se van entrecruzando, causando en el "contrapunto" que se forma entre los diferentes niveles narrativos, la desorientación que en un primer momento experimenta el lector. El autor distingue ocho personajes que prestan sus voces a la narración, c identifica dos transmisores por los cuales pasa la mayoría de la información contenida en los fragmentos. Los localiza en términos de tiempo y de espacio: "1) después de la muerte de Juan Preciado, en su tumba; 2) después de la muerte de Susana pero antes de la de Pedro, cn el equipal de éste." (p. 46) Además de cstas dos voces principales, Peavler señala las perspectivas que orientan la acción en las voces de Susana San Juan, del Padre Rentería, de Fulgor Sedano, y de Gerardo Trujillo. Una vez reconocidas y scparadas las varias perspectivas de la novela, es posible "desenmarañar el argumento." (p. 60) 
El capítulo siguiente estudia el problema del tiempo de la obra. Peavler distingue varios órdenes temporales: el de la presentación al lector; el de la perspectiva que orienta la narración, atemporal de Juan Preciado, temporal para Páramo; el de la lectura, que coincide con el primero, pero que agrega una "dimensión durativa"; y el de la narrativa misma, la del contenido temporal de las acciones narradas. Pcavler separa claramente dos cronologías: la de los hechos narrados, y la de la perspectiva desde la que se cuentan. Mediante esta discriminación, evita que cl texto se disuclva "en cl caos." Distingue la situación atemporal del diálogo entre Juan y Dorotea, de la del contenido de los hechos narrados que se ubica en el tiempo de los vivos. Que estos hechos estén inscriplos en cl ticmpo, no significa que cstén ordenados cronológicamente, aunque sí cs posible que el lector efectúc una tarea de comprensión c identifique el orden cronológico de las distintas narrativas, que es lo que el mismo Peavler hace en $\mathrm{cl}$ resto del capítulo, de acuerdo a las ediciones de 1964 y de 1981, y más adelante en cl apéndice 3.

El capítulo sexto estudia los núcleos temporales analizados en cl apartado anterior y los relaciona con las perspectivas definidas en cl capítulo cuarto, para unir estos núclcos temporales con los personales. Los núcleos espacio-temporales de la novela que cl autor establece, emanan de las historias de Juan Preciado y de Pcdro Páramo. La primera cs narrada por la voz de Juan, micntras que la segunda se construyc a través de las observaciones acerca del cacique que hacen personajes menores de la narración. Para comprender cada núclco narrativo, es preciso saber a qué perspectiva corresponden y con qué personalidad se los asocia. El apéndice 6 establece esta correlación en la obra, mientras que los apéndices 4 y 5 aclaran quiénes son los personajes de la novela y cuando se los menciona o aparecen en $\mathrm{cl}$ texto. De acuerdo a estas indicaciones, es posible crear actitudes en el lector frente a los fragmentos y a los personajes por el hecho de estar narrados más extensamente, de mancra completa, o no fragmentada.

Siguicndo esta idca, cl capítulo séptimo trata de determinar si existe una relación entre la longitud de los fragmentos y la frecuencia de un hecho en la obra, $y$ "su importancia o su significado" en la misma. Se concluye que la frecuencia con que una idea, hecho o acción aparece, se asocia con la presentación de la obra, con su "narración", mientras que la extensión textual refleja la importancia del contenido del relato. Los apéndices 7 y 8 aportan datos numéricos a cste respecto.

La conclusión trata acerca de los problemas de la verosimilitud y de la vcracidad. La vcrosimilitud se relaciona más con cl arte de narrar que con cl contenido de lo narrado. En la novela, las perspectivas múltiples que coinciden en cicrtos aspectos de los hechos y acciones contribuyen a crear el efecto de verosimilitud. Paralclamente, la veracidad de los narradores no es puesta en duda 
por el lector, que piensa que las voces le están diciendo la verdad que ellas conocen. Finalmente, sorprende que sea posible hablar de verosimilitud y de veracidad en una obra que está contada desde la ultratumba. Los personajes, además de los hechos, se juzgan complejos, no por la forma en la que están presentados, fragmentariamente, sino más bien por los conflictos internos que llegamos a conocer, y que los constituyen como "seres de interés por sí mismos." (p. 124)

Creemos que de los libros últimamente editados sobre la obra de Juan Rulfo, ćsta cs una obra neccsaria y esperađa. Es también, sumamente clara y fácil de lecr.

Una vez desentrañado el texto de Pedro Páramo, conviene abocarnos a cstudiar a dos autores que intentan interpretaciones diversas del mismo. La primera autora que reseñamos es Aronne-Amestoy, quien incluye en su análisis las obras de García Márquez, la novcla de Juan Rulfo, y los cuentos de Julio Cortázar reunidos en Bestiario, para proponer un nuevo enfoque crítico-metodológico. Frente a la oposición entre la crítica de intención científica y las posturas que arrancan con el formalismo, y ante la dicotomía propuesta entre el texto referencial y cl autorreferencial, la autora se interesa en encontrar las convergencias más que las diferencias cntre ambas posturas críticas. Para ello, describe "las cstructuras de la significación en función de la situación comunicativa propuesta en el acto de escritura/lectura."(p. $x$ ) Encuentra tal síntesis en el texto narrativo, combinando procedimicntos de la semántica estructural y de la crítica arquelípica para llegar a una fenomenología del símbolo. El resultado es un análisis que supera la dicotomía, mediante la ubicación del texto en cl centro de dos coordenadas, aquella que lo rclaciona con la tradición narrativa, y la que lo mucstra atado a las imágenes de lo real.

La obra se compone de un texto más un nivel existencial. Relacionando $\mathrm{cl}$ texto con la tradición narrativa, la autỏa distingue tres niveles: el lingüístico, el narrativo y cl arquetípico. Si a cllos le sumamos el dominio de 'lo real', el resultado es la obra en sí. Cada nivel se encuentra incluído en el siguiente, siendo el arquetípico cl que permite relacionar el texto con lo real, con el autor y con el lector reales. Aronne-Amestoy hace suya la tarea de demistificar el texto para poder construir la obra, la cual pasará a formar parte de la tradición literaria, y servirá como punto de partida para analizar textos futuros.

De los tres autores estudiados por Aronne-Amestoy, nos interesa hacer hincapié en Juan Rulfo y en su Pedro Páramo, que marca una dirección opuesta a la trazada en el primer capítulo por la obra de García Márquez, ya que mientras ćste scñala un procéso que va del crial al jardín, la novela de Rulfo nos conduce del jardín al crial. Si García Mårquez propone la utopía en el futuro sin historia, Rulfo muestra los resultados nefastos de una pretendida regresión a la cdad de oro, 
a-histórica, que encierra a quienes la emprenden en el mundo de la muerte, y condena a Comala a una extinción cíclica.

El análisis de la autora parte de la manera en que se crean las distintas perspectivas de la novela, que luego aplica a un estudio de la relación dialéctica entre imago e imagen. La sección tercera del trabajo clasifica las unidades narrativas de Pedro Páramo, que son organizadas en la sección siguiente; en la quinta, sc hace hincapić en el paradigma de la obra y en las transformaciones que sufren los núcleos narrativos para, finalmente en la sexta parte, definir los clementos arquetípicos de la obra y ensayar una hermenéutica de la misma.

La primera sección dedicada al recurso de la perspectivación de la novela, establece cl dominio de un tipo de visión inmanente en la cual el narrador se oculta tras los personajes, ubicándose cn la voz de sus agentes. En la novela encontramos varios tipos de visión inmanente, destacándose entre cllas las voces de Juan Preciado, como un discurso de tipo testimonial, y de Pedro Páramo, como discurso perspectivado en el sentido de ser presentado a través de los puntos de vista de otros personajes. El autor se encuentra, además, en las voces de los otros pèrsonajes de la obra, sin coincidir con ninguna conciencia en particular; también interviene objetivamente, o como apuntador dramático. Sin embargo, esta presencia por sí o a través de los agentes, se va reduciendo hasta eliminarse, no para desaparecer, sino para hacerse presente en su ausencia. Tal estrategia de discurso, que se lleva a cabo cuando los agentes van perdiendo su condición de tales, a la vez que el narrador va desapareciendo como una voz del relato, hace que, en definitiva, se refuerce su presencia en el relato. El caos que genera la quiebra del orden cronológico y espacial hace que el lector sea consciente de que existe una presencia autoral que ordena los fragmentos y contra la cual él/ella choca constantemente. Este recurso, dice Amestoy, plantea, a nivel de la técnica, cl problema del engaño y la desmistificación, que es uno de los temas semánticos centrales de la novela.

Establecida la pluralidad de perspectivas, la autora hace una división entre los discursos que constituyen la obra. Por un lado, exista un discurso narrativo básico, que se expresa en el plano de la imagen, y que da cuenta del mundo 'real' al revelar la perspectiva empírica de los personajes. El discurso narrativo básico se desarrolla desde la tumba en el caso de Juan, y desde el equipal en el caso de Pedro, y se reficre a los núcleos del crial y de la culpa. Por otro lado, está el discurso interpolado de una scrie de voces líricas, de las cuales las más importantes son la voz de Dolores evocando a Comala y la de Pedro Páramo recordando a Susana; sus voces generan el plano de la imago, y establecen una perspectiva mítica. Se refieren a entidades ideales perdidas: un lugar en cl caso de Dolores, una relación en el de Páramo: El lugar y el tiempo de estas voces, se encuentra en la conciencia interior de los personajes y no coinciden con los del discurso básico. 
Ambos discursos, el básico y el interpolado, se relacionan en una especic de contrapunto que se da lo largo de la obra, tanto perspectivo como semántico, y hace presente la imago idcal, mítica, del paraíso en el erial, y la imago del amor en cl contexto de la culpa. En la intersección de los dos discursos se constituyen las acciones del mundo narrado. El contrapunto no es estático, de tal manera que uno termina dominando al otro; no se da entre los discursos una integración, sino una rclación de dominio y disolución entre la imagen empírica y la ideal, disolución que se manifiesta en el plano semántico, en el temporal y en el del orden humano, y que culmina con la anulación de la imagen por la hipertrolia de la imago.

Esta disolución del plano básico en el mítico, se repite a través de la estructuración de la obra. Al clasificar las unidades narrativas en la sección tercera, la autora se basa en el símil del mosaico para caracterizar la estructura de Pedro. Páramo. En la sección IV, reconstruye y clasilica las secuencias básicas mediante la ordenación con respecto a dos ejes de acción: el centrado en Juan Preciado, y cl centrado en Pedro Páramo. Ambos cjes se relacionan simétricamente, repitiendo cl mismo patrón en cada mitad de las series, y las piezas del mosaico se encuentran relacionadas por principios espacialcs de simultancísmo, yuxtaposición, superposición, simetría, elc. Para Amestoy, la disolución formal del tiempo cn cl espacio, lograda mediante la estructuración de la obra en fragmentos que forman un mosaico, connota la disolución de la dimensión histórica de lo narrado, en la dimensión mítica, que ya había señalado a nivel de la relación entre imagen-imago. "El mosaico imbrica realismo y mito, y termina por disolver el primero en el último." (p. 86)

En la sección V, al hablar dei paradigma y de las transformaciones, la autora destaca que el sintagma del mosaico no encadena los núclcos narrativos de Juan y de Pedro, sino que los imbrica para constituir un eje único de la acción. La misma adquicre una estructura circular, no a causa del tiempo mítico del eterno retorno, que no es cl que domina en la obra, sino por una elección libre de Juan; este "incurre cn lacircularidad, no por falta de opción, sino por incapacidad de asumir la opción." (p. 89) Juan renuncia a quebrar la determinación que le impone su carácter de 'hijo de', tanto en relación a Dolores, su madre, comocon Pedro Páramo, su padre. Tiene la oportunidad de romper la circularidad de la historia cuando se encuentra en la casa de los hermanos. Entonces quiere irse a Sayula, pero no puede hacerlo; tampoco asume un compromiso frente a la realidad que se le impone: un pucblo moribundo y una mujer que se le ofrece; se nicga a hacerse cargo de su situación presentc y mucre: lo mata "la ilusión" (Páramo p. 128) aunque, según observa Dorotea, se encontró "como mueren los que mueren mucrtos de micdo."(Páramo p. 126) 
Toda la acción presentada por el mosaico, resulta en la hipertrofia de lo pasado, del recuerdo y del ideal, sobre el presente, la experiencia y la historia. Amestoy hace una interesante observación acerca de la relación entre ésta y la novela; la obra, comúnmente tachada de a-histórica debido a la preponderancia de la visión ideal, al quebrantamiento del orden cronológico y de las relaciones de causalidad, y a la circularidad de la narración, se revela a los ojos de la autora como comprometida con la situación histórica mediante la calificación negativa del mundo narrado. La metáfora, si existe una, es que la marginación del horizonte histórico y la incapacidad de asumir una situación determinada para modificarla, conduce al mundo muerto, desvastado, y alienado de Comala.

En la última sccción del capítulo dedicado a Rulfo, Amestoy cstudia los arquetipos y la hermenéutica. Aquellos se basan, ya en la figura del padre, ya en la de la madre. Para la autora, esta última es más importante que la primera, debido a que su presencia es la que impulsa la acción: por ejemplo, Juan va cn busca de los valores maternos a Comala, no de los paternos. Aronne-Amestoy señala que cl modelo iniciático clásico queda descartado como base para interpretar el texto, y que la búsqueda de lo femenino "es una huella arquetípica mucho más consistente"(p. 99) ya que "La mujer es una constante simbólica"(p. 99) conspicua en el mundo narrado. "Búsqueda del paraíso-descenso al inficrno, búsqueda del padre-recncuentro con la madre, son las antítesis simbólicas que vertebran el esquema arquetípico del texio." (p. 101)

La conclusión scñala que Pedro Páramo es un laberinto clausurado: Comala, sin un sentido válido, repitiéndose circularmente hasta la náusea. No obstante, la forma estética que presenta, sugierc la posibilidad de una apertura de la narración. Dicha apertura a distintas interpretaciones ha sido explorada por Paul B. Dixon en cl tex to que a continuación estudiamos.

Para una segunda lectura de Pedro Páramo hemos tomado en consideración a Paul Dixon. Este autor ha elegido cuatro textos clásicos de la narrativa latinoamcricana: Don Casmurro (p. 1900) de Machado de Assis, Grande Sertao: veredas (p. 1956) de Joao Guimaraes Rosa, Pedro Páramo (p. 1955) de Juan Rulfo, y Cien años de soledad (p. 1967) de Gabricl García Márquez. En las cuatro obras, Dixon examina el concepto de ambigüedad y la manera en que se presenta. Su concepto no es la acepción amplia del concepto, en el sentido de multivalente, poco claro, o cnigmático; cl sentido del término para Dixon cs más restringido que estas definiciones. Para él la ambigüedad es un tema que puede dar origen a un género estructuralmente determinado, análogo al fantástico de Todorov. Las novelas elegidas son variaciones, pues, sobre un mismo tema que permite leer las diferentes aperturas que la forma estética, la palabra narrativa de la obra, nos revela. 
Basado en la percepción visual del dibujo de Penrose \& Penrose, y de otros csquemas visuales, y siguiendo la definición del concepto de Shlomith Rimmon en su obra The Concept of Ambiguity- The Example of James, Dixon toma una de las accpciones lógicas de ambigüedad basada en la opcración de disjunción. Una disjunción puede ser débil o inclusiva, o fuerte o exclusiva. Es débil cuando acepta que una proposición $a$ sea verdad, una segunda proposición $b$ sea verdad, y que ambas sean verdaderas simultáncamente. Una disjunción exclusiva coincide en los dos primeros casos, pero no acepta, a diferencia de la inclusiva, que ambas proposiciones puedan ser verdaderas simultáneamente. Se resume la idea diciendo que "la ambigücdad es una 'conjunción' de proposiciones en disjunción cxclusiva"(p. 6). Las proposiciones relacionadas mediante cstas operaciones pueden ser de dos tipos: referenciales y no referenciales; las primeras representan un objeto matcrial del mundo externo, las últimas se refieren a ideas u objeios inmateriales. Se relacionan entre sí las proposiciones de igual o de diferente tipo, dando lugar a tres posibles combinaciones. Nos interesa, en el caso de la literatura, aquella disjunción fucre que relaciona una proposición referencial con una noreferencial. Llama la atención que el autor no cita el texto de William Empson, acerca de las clases de ambigüedades. Scgún esta clasificación, la ambigüedad que reficre Dixon estaría comprendida en los tipos tercero y cuarto que refiere de Empson.

El estudio que Dixon hace de las obras, propone interprelaciones que son producto de la cxistencia de dos o más centros de orientación que resultan estar en contradicción exclusiva, más que de la ausencia de esos centros de orientación. La obra asi concebida deja de estar totalmente abierta a lecturas posibles, para quedar abicrta a medias es decir, es posible ensayar más de una lectura, pero no un número infinito de cllas. Las reacciones que la estructura ambigua de los textos provocan en el lector son de dos tipos. La primera es la de releer el texto, lo que hace que el lector se confronte con la obra de una manera más intima, despojándose de su aclitud de lector automático. Pasado el primer momento, y probado el fracaso de resolver la ambigüedad mediante la búsqueda cuidadosa de clementos textuales, una segunda reacción puede ser la de darse por vencido y abandonar el texto. De por sí, csta reacción es importante ya que conlleva el reconocimiento de que se está frente a una obra de arte, a un artificio, a una ilusión, pasando a segundo plano $\mathrm{el}$ hecho de que este artificio no se pueda desentrañar. Una tercera posibilidad es que, pasado el segundo momento de desilusión, el receptor retome el texto, y acepte las reglas de juego propuestas por la obra, de mancra que la lectura oscilc cntre un creer y un no crecr, entre una suspensión de la sospecha de irrealidad, al aceptar cl texto como objeto estético, y la sensación de cstar siendo engañado, al lecrlo como icstimonio de una realidad que no existe. Sólo es posible hablar de ambigüedad si 
se tiene en cuenta, primero, la referencialidad del lenguaje, opuesta a la cual se presenta la autorreferencialidad del texto concreto; en el espaciode la comparación entre una realidad posible y una crcada, actúa esta ambigücdad.

Lo expuesto se ve con claridad en Pedro Páramo. Es posible según Dixon, cfectuar tres lecturas del texto, pero no simultaneamente, ya que ellas se encuentran relacionadas mediante disjunciones exclusivas. La primera lectura muestra la historia lincal, la segunda, la narración fragmentada tal como se presenta, y la tercera se basa en la estructura especular de la obra. En el fondo la dos primeras corresponden a las lecturas de imago e imagen de Aronne-Amestoy, y la segunda cstá relacionada con las interpretaciones mítica y existencial de Lorente-Murphy.

Para Dixon, la lectura que desarrolla la historia de Pedro Páramo es la más obvia; reconoce, no obstante, que no es tan sencilla como parece a primcra vista. Dentro de una historia relativamente univoca, hay lagunas que desalian al lector a resolverlas. La primera duda que aparece en el lector es si los personajes están vivos o mucrtos, quićn está vivo y quién no, y cuándo han muerto estos últimos. La dicotomía entre vida-muerte y las incongruencias que a este respecto se presentan, ponen al lector ante una situación que no es posible resolver mediante una lectura más o menos atenta de la obra. Tampoco queda claro qué tipo de relación mantienc Susana San Juan con su padre Bartolomé. Se ha dicho que tienen un vínculo incestuoso, idea que se refucrza por la ambigücdad con que está presentado cl marido muerto de Susana, Florencio. Parece ser a veces un hombre que existió; en otras instancias puede ser tomado como una visión idealizada de Pedro Páramo, que Susana manticne desde su niñez y que 'muere' cuando ella reconoce al Pcdro 'rcal', o tambićn, como un sustituto de la figura paterna de Bartolomé. Abundio es otro de los personajes que presentan problemas de interpretación. Es quien aparcee al principio y al final de la obra, reforzando, para muchos, la circularidad de la misma; pero cabe preguntarse, como lo hace Dixon, si el Abundio del principio es el mismo que el del final, o si hay dos Abundios. El primero se identifica sólo por su nombre, y, para Eduviges, es sordo, aunque parece oír cuando habla con Juan. El segundo se llama Martínez de apellido, y aunque escucha, es posible mantener que es sordo, debido a la ambigüedad de las descripciones y de los diálogos en algunas instancias. La mucrte del cacique es otro acontecimiento descripto sin precisión, donde no se sabe exactamente si, además de Páramo, Abundio mata también a Damiana. Los datos señalados, la identidad de Florencio, la cxistencia de dos Abundios, la relación de Susana con su padre, ctc. son grietas en la comprensión lineal de la novela que impulsan al lector a resolverlas mediante una lectura más atenta.

La segunda manera de leer la novela es calificada por Dixon como expresionista. Para Dixon una lectura expresionista es la que toma en cucnta cl discurso $\mathrm{cn}$ 
sí, más que el referente que el discurso señala. Así como es posible analizar las conexiones entre fonemas, morfemás y palabras en la formación de una frase, así es posible cstudiar las conexiones entre las unidades narrativas de la novela y tener una noción de la estructura sintáctica de la misma. Para Dixon existen dos fuerzas sintácticas que actúan en la novela en general, y ellas son: causalidad y orden cronológico. Pedro Páramo, como otras narrativas, tiene una sintaxis basada en esas fucrzas, pero su sintaxis no se corresponde con la que presentan los fragmentos que la componen en el texto. Frente a una sintaxis que se basa en la historia lineal de la obra y de sus personajes, es posible encontrar una segunda, construida mediante las relaciones entre los fragmentos, la cual no está regida precisamente por la causalidad o por el orden cronológico; los segmentos se relacionan entre sí mediante repetición de palabras, imágenes o frases. Ambas sintaxis están relacionadas analógicamente a la manera en que la gramática transaccional relaciona las estructuras de las frases. La lectura que respeta la causalidad scría la estructura profunda de la obra, mientras que aquella que la viola, sería la estructura de superficie de la misma. Esta última, sin embargo, no es sólo un adorno, sino que impone sus reglas a la primera, y en varias instancias del relato, la contradice y problematiza, para que no se reordenen los fragmentos, sino que se aprehendan en cl orden y de la manera en que están presentados, tal como lo proponía Aricl Dorfman. De esta forma, más que una descripción de la realidad, cl lector obtiene una expresión de ella.

No cs posible en una misma opcración, percibir la lectura lincal y la expresionista de mancra simultánca: "Story and discourse each call attention to themselves, and cach distracts from the other" (p. 79). La lectura expresionista cs caracterizada por Dixon mediante cl título que Juan Rulfo quería, en principio, ponerle a su novela: "Los murmullos". Se altcrna con la lectura lineal, tomando a ratos cada una de ellas la rienda de la narración.

Finalmente, Dixon reconoce una tercera posibilidad de aprehender la novela, basada en su estructura especular: "Pedro Páramo seems to be structured upon a system of dual motifs that causes the first half of the novel to mirror the second half in reverse." (p. 82) Hay un eco entre los fragmentos, dado por palabras, frases, temas que se repiten en las dos mitades, unidas (o separadas) entre sí por cl momento cuando Juan Preciado toma conciencia de su mucrte. La estructura especular que se propone refuerza a veces a las otras dos ya analizadas, y a veces las contradice, de manera tal que el lector se encuentra con tres lecturas posibles de la obra, cada una distinta y a veces contraria a las otras, por lo cual, en el sentido que Dixon había dado al término, es acertado afirmar la ambigüedad de Pedro Páramo. 
Hemos visto la obra de Rulfo desde tres perspectivas de análisis: la primera, de Llorente-Murphy, se ocupaba de la ubicación histórica de dicha obra; la segunda, de Peavler, la estudiaba a partir de la forma; de los puntos de vista, que incluyen la mirada y la voz; y de los núcleos narrativos temporales. La tercera perspectiva de análisis tomaba en cuenta cl contenido de Pedro Páramo y proponia diversas claves de lectura: Aronnc-Amestoy estudiaba una lectura emparentada con los conceptos de imago y de imagen, y Dixon, otra relacionada con el concepto de ambigücdad. Estas diversas perspectivas de análisis prucban ser fructíferas en su aplicación al texto rulfiano, al que enriquecen, si cabe, agregando sentidos a una obra que los busca constantemente. 


\section{BIBLIOGRAFIA.}

Aronne-Amestoy, Lida. Utopía, paraíso e historia. Inscripciones del mito en - García Márquez, Rulfo y Cortázar. Purdue University Monographs in Romance Languages. (p. 19). Amsterdam/Philadelphia: John Benjamins, 1986.

Dixon, Paul B. Reversible Readings. Ambiguity in Four Latin American Novels. Alabama: The University of Alabama Press, 1985.

Dorfman, Aricl. "En torno a Pedro Páramo de Juan Rulfo." Ilomenaje a Juan Rulfo. Ed. Helmy F. Giacoman. New York: Las Américas, 1974.

Empson, William. Seven Types of Ambiguity. New York: New Directions, 1930.

González Boixo, José C. Claves narrativas de Juan Rulfo. Lcón: Colegio Universilario de León, 1980.

Lorentc-Murphy, Silvia. Juan Rulfo: realidad y mito de la Revolución Mexicana. Madrid: Plicgos, 1988.

Peavler, Terry J. El texto en llamas. El arte narrativo de Juan Rulfo. New York: Peter Lang, 1988.

Rimmon-Kenan, Shlomith. The Concept of Ambiguity. The example of James. Chicago: Chicago UP, 1977.

Rulfo, Juan. Pedro Páramo. México. Fondo de Cultura Económica. Letras Mexicanas, 1955.

. Pedro Páramo. México: Fondode Cultura Económica. Colccción Popular, 1964.

.PedroPáramo. Ed. Luis Leal. New York: Appleton-Century-Crofts, 1970.

- Pedro Páramo. 2a cd., revisada por el autor. México: Fondo de Cultura Económica. Colccción Popular, 1981.

. Pedro Páramo. Ed. González Boixo. Madrid: Cátedra, 1983. 
